\title{
Electrochemically Triggered Michael Addition on the Self-Assembly of 4-Thiouracil: Generation of Surface Confined Redox Mediator and Electrocatalysis
}

\author{
C. Retna Raj*, S. Behera \\ Department of Chemistry, \\ Indian Institute of Technology, Kharagpur 721302, India \\ Fax: +91-3222-282252, 2825303; Tel: +91 3222283348 \\ E-mail: crraj@chem.iitkgp.ernet.in
}

\section{Supporting Information}

\section{Figure 1S}

(A) Cyclic voltammograms obtained for CA $(50 \mu \mathrm{M})$ on 4-TU monolayer-modified electrode at different scan rates in 0.1 M PBS of pH 7.2. Scan rate: 10, 50, 100, 150, 200, 250, 300, 350, 400 and $500 \mathrm{mV} / \mathrm{s}$. (B) Plot of $I_{\mathrm{p}}{ }^{\mathrm{c}}\left(\mathrm{I}_{\mathrm{red}}\right)$ vs. square root of scan rate. (C) Plot of $I_{\mathrm{p}}^{\mathrm{c}}\left(\mathrm{II}_{\mathrm{red}}\right)$ vs. scan rate.

\section{Figure 2S}

(A) Cyclic voltammograms obtained for CA $(0.5 \mathrm{mM})$ in the (a) absence and (b) presence of 4-TU (0.5 mM) on an unmodified Au electrode in 0.1 M PBS (pH 7.2). Scan rate 100 $\mathrm{mV} / \mathrm{s}$. (B) Voltammogram obtained for the same electrode in $0.1 \mathrm{M}$ PBS without CA.

\section{Figure 3S}

Cyclic voltammogram obtained for $\mathrm{Au}-2 \mathrm{TU}$ electrode after the reaction of electrogenerated $o$-quinone with the self-assembly in $0.1 \mathrm{M} \mathrm{PBS}$ of $\mathrm{pH}$ 7.2.

\section{Figure 4S}

Cyclic voltammograms obtained for (a) bare Au and (b,c) Au-4TU electrodes in the presence of $50 \mu \mathrm{M}$ of (A) DOPAC and (B) MCA in $0.1 \mathrm{M}$ PBS of $\mathrm{pH} 7.2$; b and c represent cyclic voltammograms obtained at the $1^{\text {st }}$ and $10^{\text {th }}$ sweeps. Insets show the 
cyclic voltammogram obtained for the Au-4TU electrode after the electrochemical reaction in $0.1 \mathrm{M}$ PBS in the absence of DOPAC and MCA. Scan rate $100 \mathrm{mV} / \mathrm{s}$.

\section{Figure 5S}

Plots illustrating the effect of (A) electrolysis potential, (B) electrolysis time and (C) concentration of $\mathrm{CA}$ in the generation of redox mediator.

\section{Figure 6S}

Cyclic voltammograms obtained for the oxidation of NADH $(0.5 \mathrm{mM})$ on (a) unmodified $\mathrm{Au}$ and (b) Au-4TU electrodes. Scan rate $100 \mathrm{mV} / \mathrm{s}$.

\section{Figure 7S}

(A) Cyclic voltammograms illustrating the electrocatalytic activity of Au-DPTU electrode in 0.1 M PBS towards oxidation of NADH at different concentrations. [NADH]: (a) 0, (b) 0.1, (c) 0.2, (d) 0.3, (e) 0.4, (f) 0.5, (g) 0.6, (h) 0.7, (i) 0.8, (j), 0.9, (k) 1, (l) 1.5, (m) 2, (n) 3, (o) $4 \mathrm{mM}$. Scan rate $100 \mathrm{mV} / \mathrm{s}$. (B) Corresponding calibration plot.

\section{Figure 8S}

Amperometric traces obtained for the sensing of NADH in the (a) absence and (b)

presence of $\mathrm{Ca}^{2+}(28 \mathrm{mM})$. The electrode was polarized at $0.22 \mathrm{~V}$ and $1 \mu \mathrm{M}$ of NADH was injected in the stirred supporting electrolyte solution. The noise is due to the stirring of supporting electrolyte. 

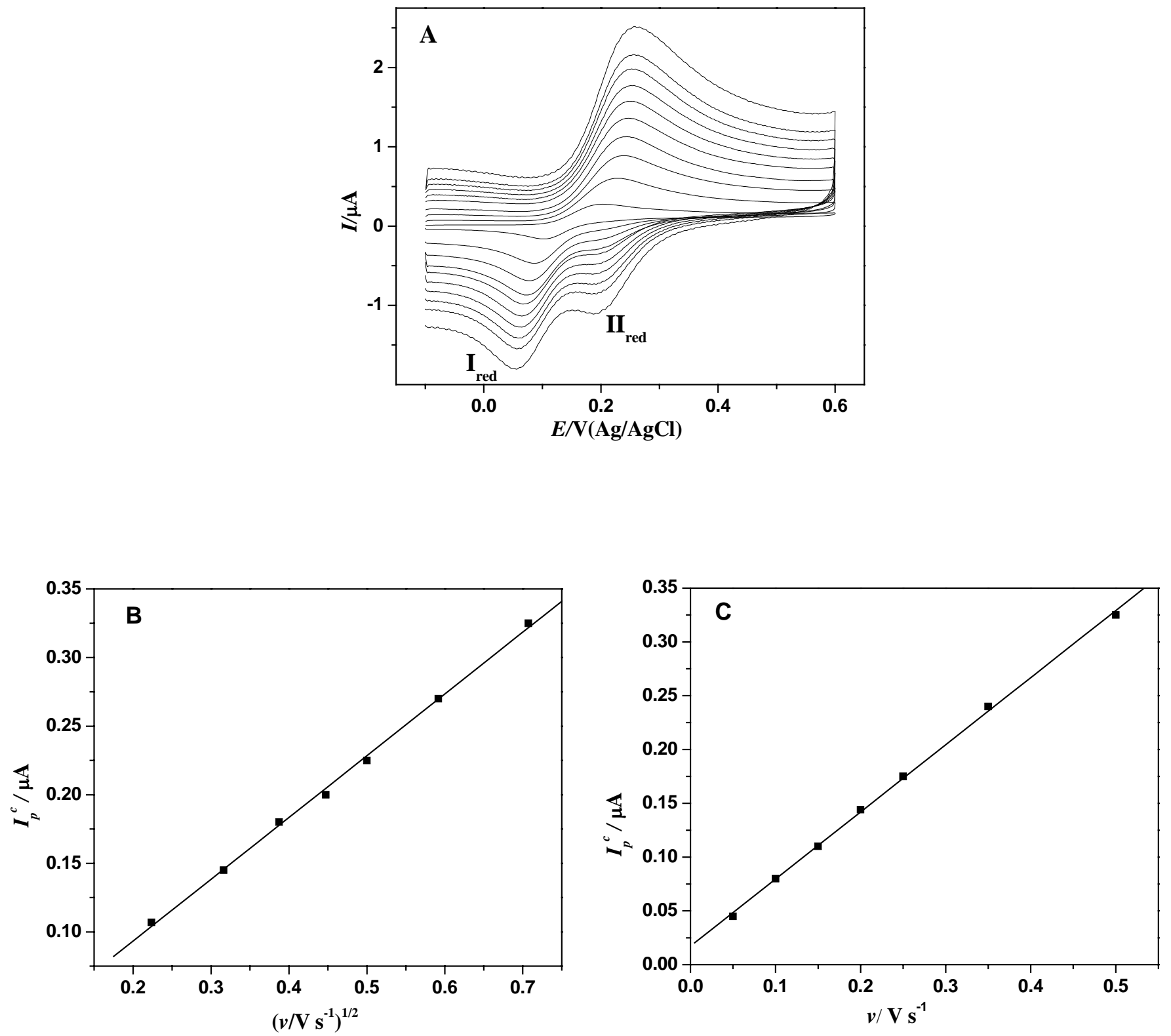

Figure 1S

C.R.Raj 

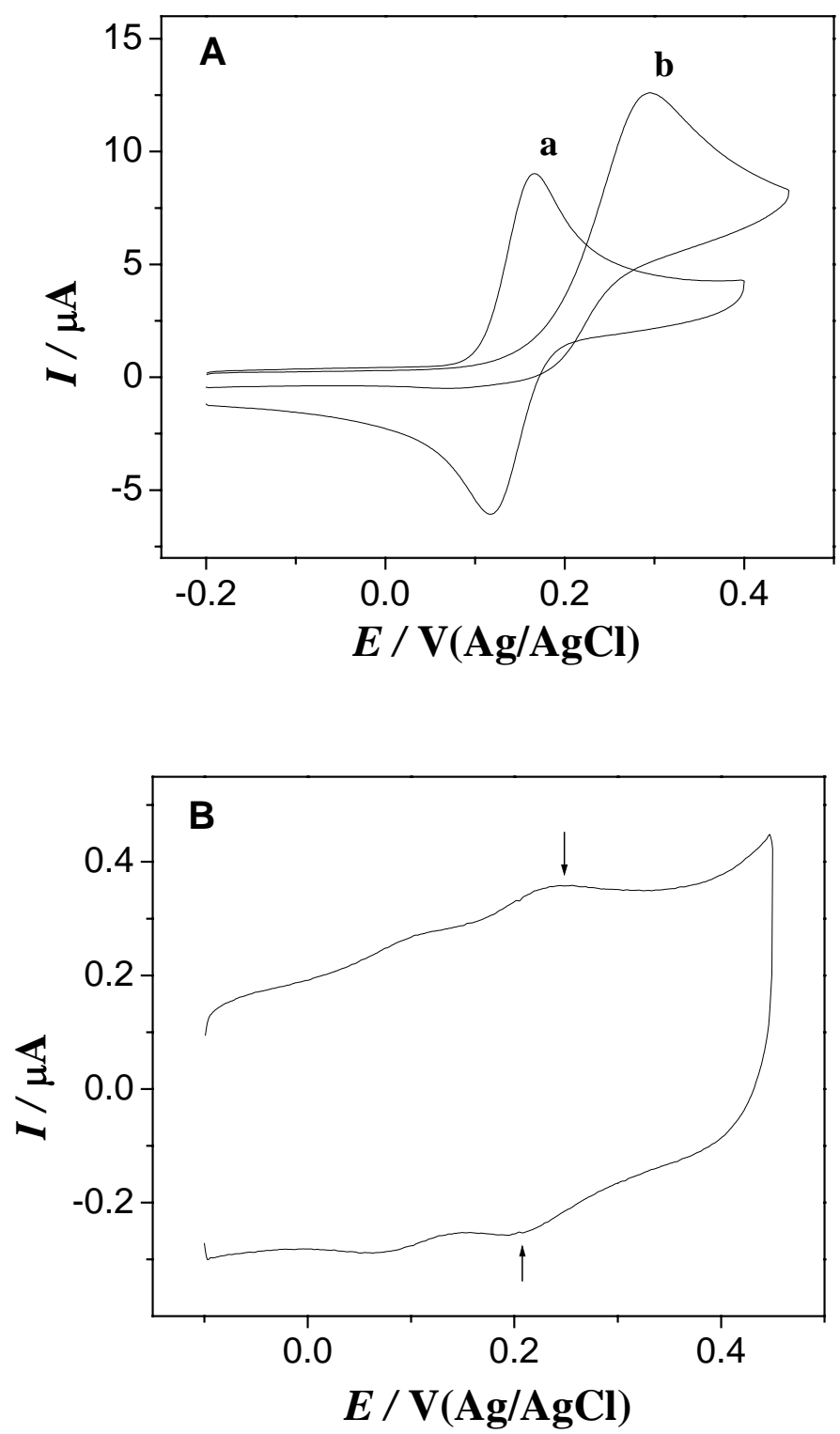

Figure 2S

C.R.Raj 


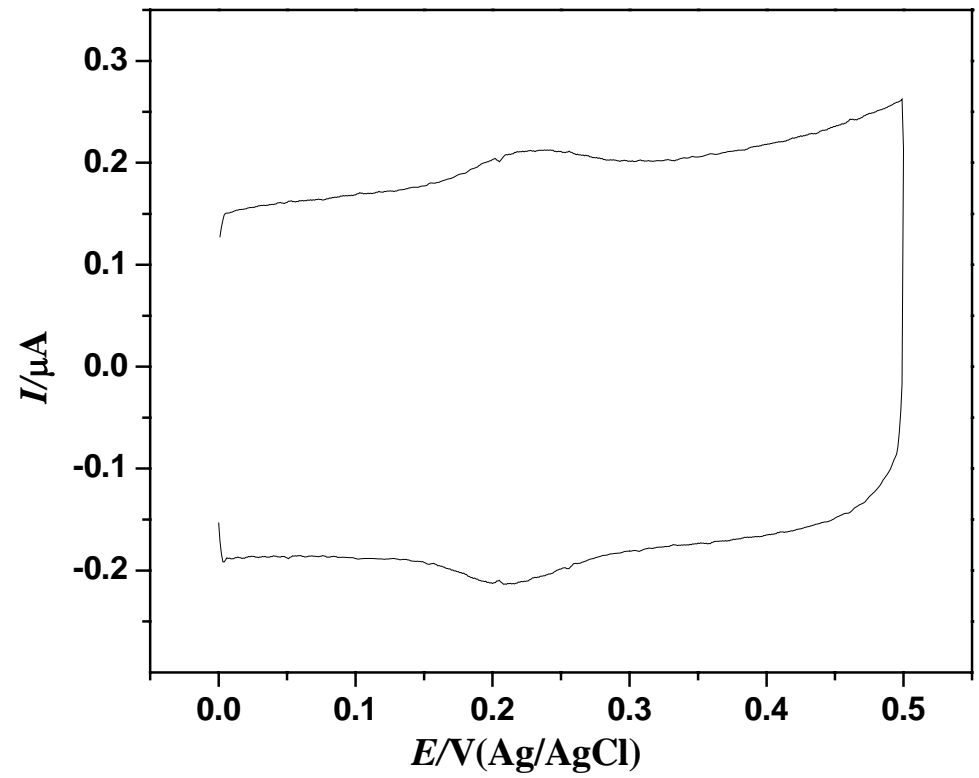

Figure 3S

C.R.Raj 

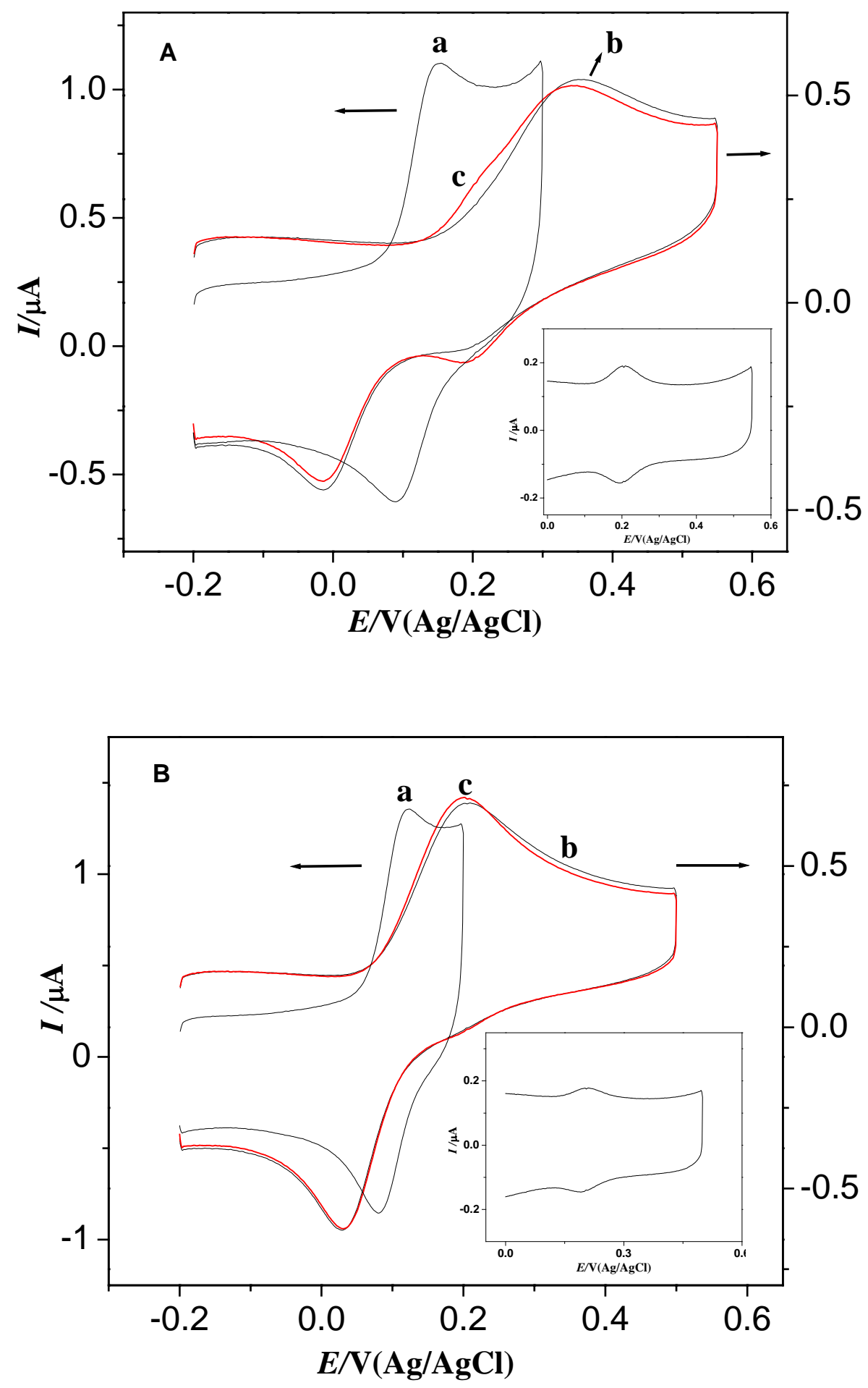

Figure 4S C.R.Raj 

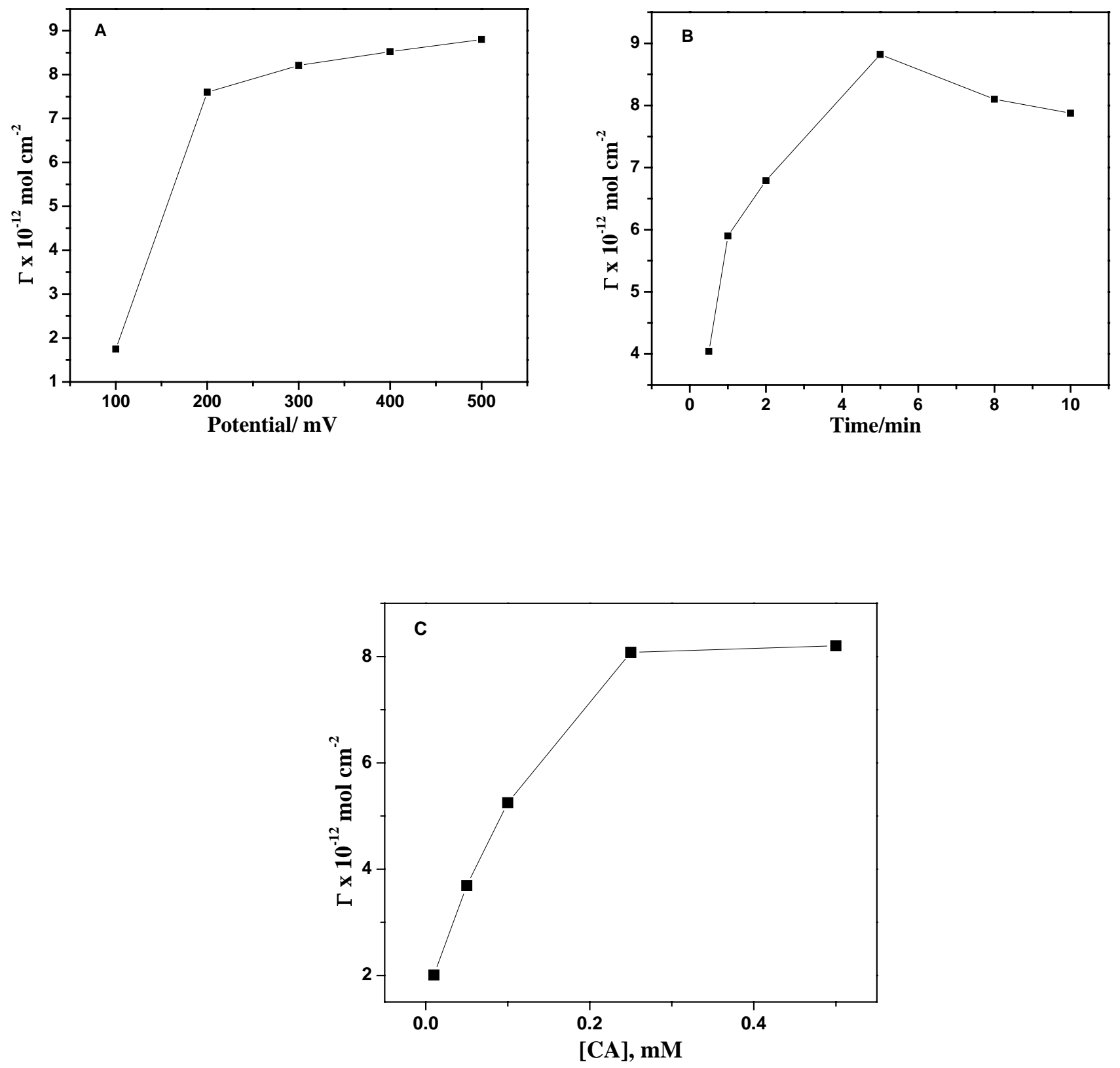

Figure 5S 


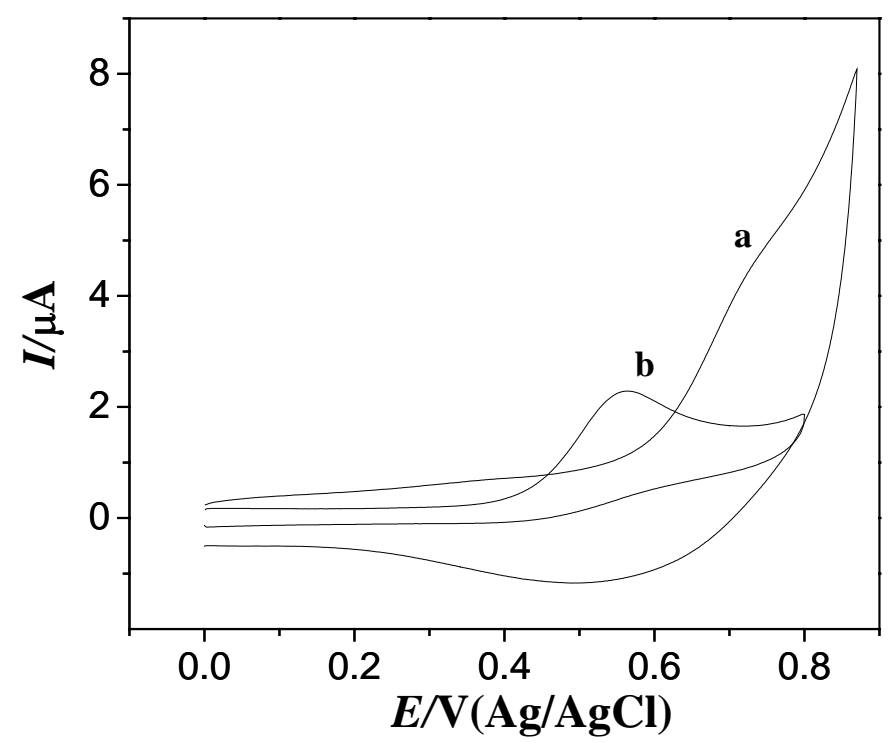

Figure 6S

C.R.Raj 

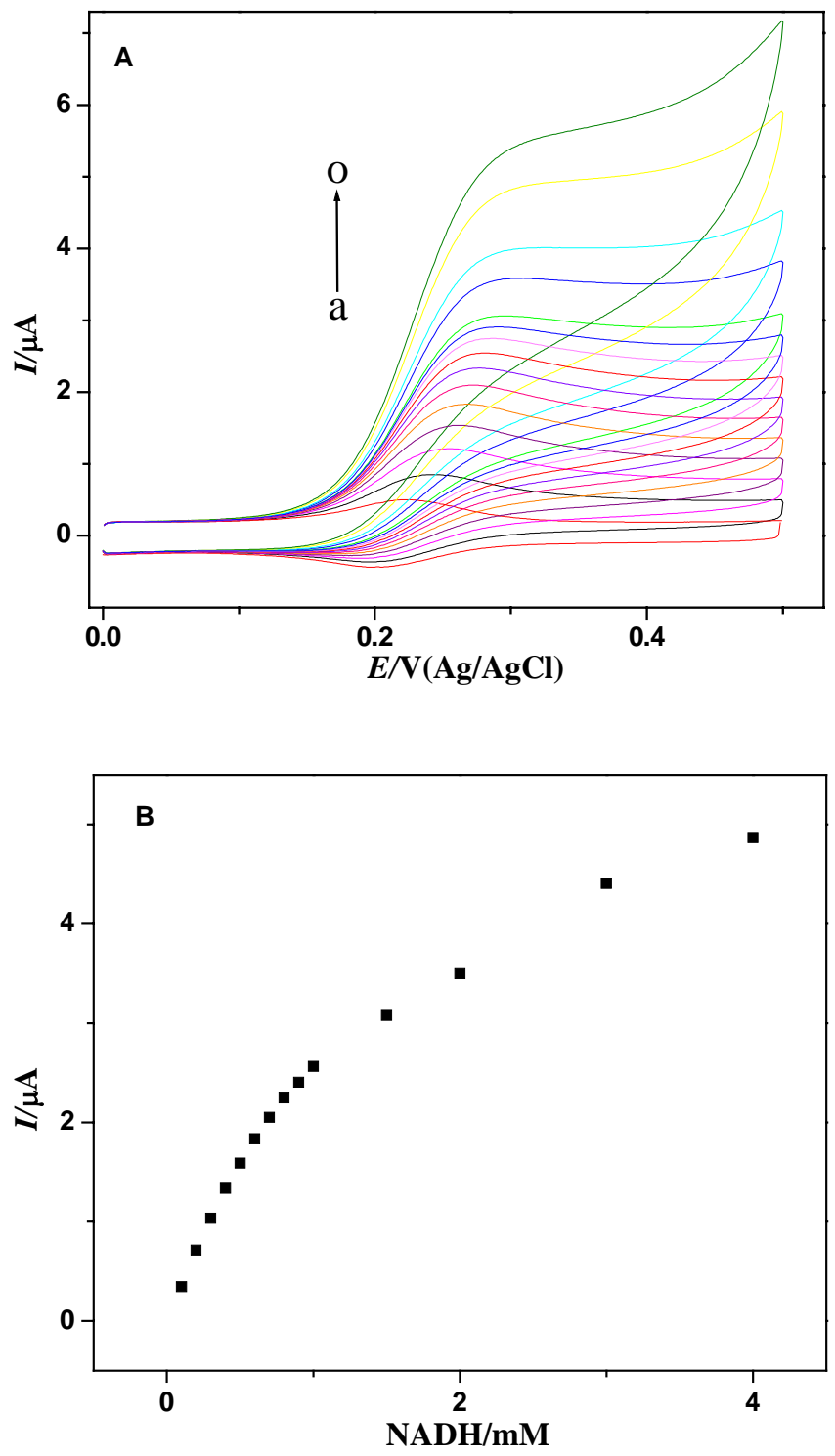

Figure 7S

C.R.Raj 


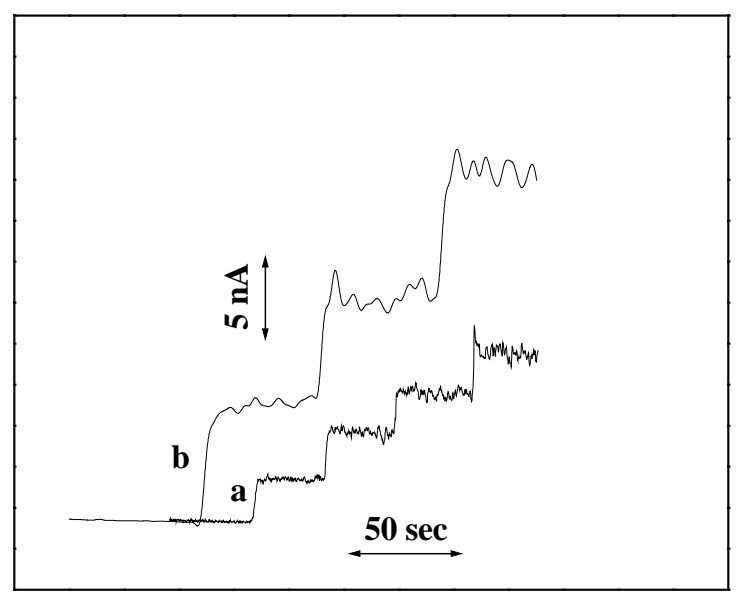

Figure 8S

C.R.Raj 